NBER WORKING PAPER SERIES

STRICT LIABILITY VERSUS NEGLIGENCE

IN A MARKET SETTING

A. Mitchell Polinsky

Working Paper No. 420

NATIONAL BUREAU OF ECONOMIC RESEARCH 1050 Massachusetts Avenue

Cambridge MA 02138

January 1980

The research reported here is part of the NBER's research program in Law and Economics. Any opinions expressed are those of the author and not those of the National Bureau of Economic Research. 


\title{
Strict Liability Versus Negligence \\ in a Market setting
}

\begin{abstract}
$\underline{\text { ABSTRACT }}$
Bo:h strict liability and negligence are efficient in the short run when the number of firms causing harm is fixed. Only strict liability is efficient in the long run when the number of firms is variable. In general, the market price in the long run under negligence is too low and too many firms enter the industry. However, the optimal second-best negligence standard may result in the same price and number of firms as under strict liability.
\end{abstract}

A. Mitchell Polinsky Stanford Law School -orDepartment of Economics Stanford University Stanford, CA 94305 (415) 497-0886 


\section{STRICT LIABILITY VERSUS NEGLIGENCE}

\section{IN A MARKET SETTING}

A. Mitchell Polinsky */

There are two competing rules of liability for controlling activities like speeding or polluting which cause harm to others. The rule of strict liability shifts the victim's harm to the injurer regardless of the injurer's behavior, while the rule of negligence shifts the burden to the injurer only if the injurer does not take some specified amount of care.

Most formal analyses of strict liability and negligence have been in a non-market context like automobile accidents. $1 /$ These studies conclude (or imply) that both rules are efficient when the administering authority has sufficient information to set the negligence standard properly (in each case a defense of contributory negligence may be required). Áccording to these analyses, strict liability is efficient because it fully internalizes the harm and negligence is efficient because the injurer can be induced to take exactly the specified amount of care and this amount can be set efficiently: For reasons which will become apparent, it is important to note that these models have assumed a fixed number of injurers--for example, a predetermined number of drivers.

Interestingly, most informal discussions of strict liability and negligence have suggested that in a market setting negligence may be inefficient even when the administering authority has perfect information. The argument is stated clearly in a discussion of environmental control by Richard Stewart and James Krier: Reflecting pollution costs in product prices. If 
strict liability is not imposed for the residual damages caused by partially controlled polluting activity, these damages will not be reflected in the price of commodities produced by such activity. As a result, commodities with whose production pollution is associated will be underpriced relative to commodities whose production causes no pollution, resulting in resource misallocation. [p. 227] $\frac{2 /}{4}$ This paper formally analyzes strict liability and negligence in a market setting. The discussion emphasizes the impact of the rules on the market price and on the number of firms in the industry. For simplicity, the damage caused by each firm is assumed to be determined only by that firm's "care" (and not also by the firm's output or the victim's behavior). $3 /$

The argument that both strict liability and negligence are efficient is correct in the short run when the number of firms causing harm is fixed. The market price in the short run is the same under strict liability and negligence despite the fact that under the rule of negligence firms do not bear the cost of their harmful activity. The argument that only strict liability is efficient is correct in the long run when the number of firms is variable. When the negligence standard corresponds to the efficient level of care, the market price in the long run under negligence is too low and too many firms enter the industry. However, when the standard is chosen optimally, taking into account the inefficiency of the negligence rule, the standard exceeds the efficient level of care, the price rises, and the number of firms falls. The optimal secondbest standard may actually result in the same price and number of 
firms under negligence as under strict liability. $\underline{4}$

\section{The Model}

The analysis of strict liability and negligence is undertaken in a very simple partial equilibrium model of a competitive industry composed of $\mathrm{n}$ identical firms. Each firm's cost of producing $q$ units of output is $\mathrm{C}(\mathrm{q})$. The average cost function is assumed to be Ushaped. Each firm's cost of taking z units of care is $z$ (care is defined so that one unit costs one dollar). Associated with each firm's level of care is an external damage $D(z)$. Damages decrease with care. Let $\mathrm{P}(\mathrm{s})$ be the industry's inverse demand function, where $\mathbf{s}=n q$ is aggregate output. Social welfare $\mathrm{w}$ equals the benefits to consumers of output nq (assumed to be approximated by the area under the industry's inverse demand curve), less the cost of producing $\mathrm{nq}$, the external damages, and the cost of taking care:

$$
w=\int_{0}^{n q} p(s) d s-n c(q)-n D(z)-n z .
$$

In the short run, the number of firms is fixed. $\underline{5}$ The social optimum is defined by the $\mathrm{q}$ and $\mathrm{z}$ which maximize social welfare. From (1) the first-order condition (all solutions are assumed to be unique interior local optima) with respect to $q$ may be written as

$$
P(n q)=C^{\prime}(q)
$$

This has the usual interpretation that price equals marginal cost. The first-order condition with respect to $\mathrm{z}$ is:

$$
-D^{\prime}(z)=1
$$


This states that the marginal benefits from an increase in care-reduced damages--equals the marginal cost of greater care.

In the long run, the number of firms is variable. The social optimum is now defined by the $q, z$, and $n$ which maximize social welfare. From (1) the first-order condition with respect to $\mathrm{n}$ can be written as

$$
P(n q)=[C(q)+\Gamma(z)+z] / q
$$

This has the usual interpretation that price equals average cost. The social welfare maximizing values of the variables will be indicated by an asterisk.

\section{Short-Run Analysis}

Under strict liability, each firm's problem is to maximize revenues less production costs, external damages, and the cost of taking care:

$$
\underset{q, z}{\operatorname{Max}} P q-C(q)-D(z)-z .
$$

The first-order conditions with respect to $q$ and $z$ are, respectively,

$$
\begin{aligned}
& P=C^{\prime}(q), \\
& -D^{\prime}(z)=1,
\end{aligned}
$$

which coincide with the social optimum. This is not surprising since strict liability fully internalizes the externality.

Under negligence, let $\bar{z}$ be the standard of care. Each firm's problem is: 


$$
\operatorname{Max} P q-C(q)-\bar{D}(z)-z \text {, }
$$

where

$$
\begin{aligned}
& q, z \\
& \bar{D}(z)= \begin{cases}0 & \text { if } z \geq \bar{z}, \\
D(z) & \text { if } z<\bar{z} .\end{cases}
\end{aligned}
$$

The first-order condition with respect to $\mathrm{q}$ is the same as (6). It is easily shown that when $\bar{z}=z^{*}$, the level of care chosen by each firm is $\bar{z}$ (see footnote 8 below). Thus, the social optimum can be reached under negligence if the standard is chosen properly--equal to the efficient level of care.

\section{Long-Run Analysis}

Under strict liability, each firm chooses output and care to maximize profits as indicated by (5), so that (6) and (7) are satisfied (implying at least that $z=z^{*}$ ). In addition, equilibrium is characterized by zero profits:

$$
P(n q) q-C(q)-D\left(z^{*}\right)-z^{*}=0
$$

This is equivalent to the condition for the social optimum that price equals average cost. Thus, strict liability is efficient in the long run.

Under negligence, assume initially that the standard is set at the efficient level of care. Firms maximize profits by choosing output and care according to (8), so that (6) is satisfied and $z=z^{*}$. The zero profit condition under negligence is therefore:

$$
P(n q) q-C(q)-z^{*}=0
$$

Tris condition, along with (6), implies that the output of each firm under negligence is too low, that the market price is too low, 
and that too many firms enter the industry. $6 /$

Since the negligence outcome is not efficient when the standard equals the efficient level of care, the optimal second-best standard is of some interest. It can be demonstrated that, optimally chosen, $\bar{z}>z^{*}$. I/ The reason for this is not hard to understand. Consider a slight increase in the standard starting at $\bar{z}=z^{*}$. Since firms will continue to meet the standard (they will over some range), their costs will rise and, as a conseyuence, so will the market price. This has the beneficial effect of raising the output of each firm (which was too low when $\bar{z}=z^{*}$ ) and of reducing the number of firms. The inefficiency created by inducing firms to take care just above the efficient level is negligible since the effect on social welfare of a marginal change in firms' care is zero at the optimal level of care. Thus, it is desirable to increase the standard to some extent.

There is a limit to how high the standard can be set and still induce firms to meet the standard. It is easy to show that the highest feasible standard leads to the same price under negligence as under strict liability; given this standard and the resulting price, the output of each firm and the number of firms is efficient under negligence. $8 /$ By reasoning similar to that used in the previous paragraph, it might seem, therefore, that the optimal secondbest standard should not be this high: the effect on social welfare from lowering the level of care slightly (by lowering the standard) would be beneficial while the effect on social welfare due to the resulting marginal changes in firm output and the number of firms would seem to be negligible. Perhaps surprisingly, this argument is not correct. It can be demonstrated that the optimal second- 
best standard under negligence might in fact lead to the same price, firm output, and number of firms as under strict liability.

The basis for this conclusion can be explained as follows. It is true that lowering the standard slightly from its highest feasible level improves social welfare through its effect on the level of care and leaves social welfare unchanged by its effect on firm output. It is not true, however, that lowering the standard leaves social welfare unchanged through its effect on the number of firms even though the number of firms was previously efficient. This is because the optimal number of firms given an inefficiently high level of care is less than the efficient number of firms. Since lowering the standard reduces firms' costs and consequently increases the number of firms, this effect on social welfare is undesirable. Therefore, whether the standard should be lowered depends on the strength of this effect relative to the beneficial effect on care.

\section{Discussion}

(a) The model used here can be interpreted in two ways. The most natural interpretation is that the damage from each firm's output harms individuals who are not consumers of that output (e.g., a chemical industry pollutes a lake used for recreation). The other interpretation is that the damage falls on the consumers of the firm's output but they underestimate it (e.g., food producers sell products with misperceived carcinogenic effects). Under the second interpretation the model applies as it stands if the consumers are totally ignorant of the harm. However, it is easy to modify it to allow the demand curve for the output to shift, depending 
on who bears the damage. As long as consumers underestimate the damages, the basic results will apply.

(b) In a sense, the problem discussed here with the negligence rule in a market setting is that it is not possible to apply the rule to the industry as a whole. Courts are allowed to determine only whether any particular firm is negligent with respect to the activities over which it has control. This is not sufficient to correctly regulate the number of firms in the long run since all firms are acting the same way. No firm can be held responsible for the number of firms in the industry.

(c) The same type of observation would apply in a non-market setting in which there is free entry into the injuring activity. For example, consider individuals who must decide whether to drive to a nearby city--and thereby risk hitting innocent pedestrians--or to not make the trip at all. Under a negligence rule, too many individuals will make the trip even if all who do so take the proper amount of care in driving. The earlier formal analyses of strict liability and negligence in a non-market context which concluded that both rules were efficient assumed a fixed number of injurers.

(d) A version of the entry problem with the negligence rule also can arise in a market setting in the short run. For example, suppose there are a certain number of firms operating in the short run in the absence of any regulation and that these firms have different costs of production (but, for simplicity, the same damage functions and cost of taking care). The rule of strict liability-which would still be efficient with this generalization--may drive some of the costlier firms out of business. The rule of negligence, however, may induce some firms which would have gone out of busi- 
ness under strict liability to stay in business. As in the long run, this will result in too low a price and too many firms. 10/

(e) The main point of this paper would not be affected if each firm's total damage depends both on that firm's level of care and its output. If the negligence standard is then appropriately defined both with respect to the firm's care level and its output, the present analysis would apply essentially unchanged. If, however, the negligence standard is still defined just in terms of care (as is usual in practice), there would be an additional problem with the negligence rule besides the entry problem: it would distort the firm's choice between care and output. $11 /$

(f) Some of the conclusions of this paper may be affected if the total damage depends both on the firm's actions and the victim's behavior (e.g., the care exercised in using a lawn mower). If the number of potential victims is fixed--so there is no "entry issue". on the victim's side--then the present results would be essentially unchanged (putting aside the separate issue discussed in the previous comment). An appropriate defense of contributory negligence-in which the firm would be free of liability if the victim did not take his efficient amount of care--should in principle be added to both the strict liability and negligence rules. In equilibrium the victim would take the correct amount of care, so the strict liability and negligence rules would operate as described in this paper. If, however, the number of victims is variable, then in general neither liability rule (with a defense of contributory negligence) would be expected to be efficient. Negligence would lead to excessive entry on the injurer side, while strict liability would encourage too much entry on the victim side. $12 /$ 
Footnotes

* Law School and Economics Department, Stanford University; and National Bureau of Economic Research. Work on this paper was supported by the National Science Foundation through a grant (SOC 78-20159) to the law and economics program of the National Bureau of Economic Research. Any opinions expressed are those of the author and not those of the NBER. Helpful comments were received from participants in a number of seminars.

1/ See, for example, the paper by John Brown. The only exceptions are discussed in footnote 4 below. There are also a number of formal studies of products liability in a market context which do not compare strict liability to negligence.

2) See also the discussions by Guido Calabresi (pp. 500-17), Duncan Kennedy (pp. 54-61), and Richard Posner (pp. 137-42). Michael Spence and Martin Weitzman (pp. 216-17) make a similar point in the context of comparing taxes to standards.

3/ See comments (e) and (f) in section IV below for a discussion of how the results are affected if harm also depends on output or the victim's behavior.

4/ A recent paper by Čnto Veljanovski (pp. 17-22) uses a diagrammatic model to show that negligence is inefficient in the long run, but he does not consider the second-best problem. The paper by Steven Shavell develops some closely related issues (see comment (e) in Section IV below). Barry Weingast et al. compare strict liability and negligence when, in effect, only the consumer of a product affects the harm.

5/ If the number of firms is effectively variable in the short run due to exit, the results may be different (see comment (d) in 
Section IV below).

6/ Let $q^{0}$ and $n^{\circ}$ be the equilibrium values of $q$ and $n$ under negligence. Substituting $P(n q)=C^{\prime}(q)$ into (9) and (10) gives expressions of the form $C^{\prime}(q) q-C(q)-K=0$, where $K$ is some constant. It follows from $C^{\prime \prime}>0$ (rising marginal costs are assumed) that $\mathrm{dq} / \mathrm{dK}>0$. Thus, $\mathrm{q}^{0}<\mathrm{q}^{*}$. Since $\mathrm{P}(\mathrm{nq})=\mathrm{C}^{\prime}(\mathrm{q})$ and $\mathrm{C}^{\prime \prime}>0$, $P\left(n^{0} q^{0}\right)<P\left(n^{*} q^{*}\right)$. Thus, $n^{0} q^{0}>n^{*} q^{*}$ and $n^{0}>n^{*}$.

7/ Firms will just meet the staindard if and only if $\bar{z}$ is between zero and some $\hat{z}>z^{*}$ (see footnote 8 below). Given $\bar{z}$ in this range, it follows from substituting (6) into (10) (with $\bar{z}$ replacing $\left.z^{*}\right)$ that the equilibrium $q$ minimizes $(C(q)+\bar{z}) / q$. Let $q(\bar{z})$ be the solution to this problem. Given $q(\bar{z})$, the price is $(C(q(\bar{z}))+\bar{z}) /$ $q(\bar{z})$. Thus, nq $(\bar{z})=P^{-1}[(C(q(\bar{z}))+\bar{z}) / q(\bar{z})]$. Let $n(\bar{z})$ be the solution of this expression for $n$. Substituting $q(\bar{z})$ and $n(\bar{z})$ into (1) gives social welfare solely as a function of the standard, $W(\bar{q})$. After some manipulation, it can be seen that $\operatorname{sign}\left\{W^{\prime}\right\}=$ $\operatorname{sign}\left\{-n^{\prime} D-n\left(D^{\prime}+1\right)\right\}$. Since $n^{\prime}<0$ it follows from assuming that $\mathrm{D}(\mathrm{z})+\mathrm{z}$ is U-shaped that $\mathrm{W}^{\prime}(\bar{z})>0$ for $\bar{z} \leqq z^{*}$.

8/ If $\bar{z}<\hat{z}$, where $\hat{z}=D\left(z^{*}\right)+z^{*}$, firms will choose $\bar{z}$ because $\bar{z}<z+D(z)$ for all $z<\bar{z}$. If $\bar{z}=\hat{z}$, firms are indifferent between $\bar{z}$ and $z^{*}$. If $\bar{z}>\hat{z}$, firms will choose $z^{*}$. Thus, the highest feasible standard is $\hat{z}$ (or arbitrarily close to $i t$ ). Given $\bar{z}=\hat{z}$, it follows from the discussion in footnote 7 above that $q(\hat{z})=q^{*}$ and that the price is $\left(C\left(q^{*}\right)+D\left(z^{*}\right)+z^{*}\right) / q^{*}$; since $q$ and $P(n q)$ are the same as under strict liability, $n$ must also be the same.

9) It is sufficient to show that it is possible that $W^{\prime}(\bar{z})>0$ for all $\bar{z}<\hat{z}$. Recall from footnote 7 above that $\operatorname{sign}\left\{W^{\prime}\right\}=\operatorname{sign}$ $\left\{-n^{\prime} D-n\left(D^{\prime}+1\right)\right\}$. Since $D^{\prime}(z), n(z)$, and $n^{\prime}(z)$ are continuous functions on $0 \leqq z \leqq \hat{z}$, they are bounded. Thus, if $D(\hat{z})$ is suffi- 
ciently large, the result follows.

10/ This point is illustrated diagrammatically in the context of comparing taxes to subsidies in my paper.

11/ See Shavell's paper. Since he treats the industry as composed of one competitively behavins firm whose harm depends on care and output, he does not raise the problem of controlling the number of firms.

12) An analogous result is showr by Shavell when the damage depends on the levels of care and activity of one injurer and one victim. The same point should apply when damages depend on care and the number of injurers and victims. 


\section{$\underline{\text { References }}$}

J. P. Brown, "Toward an Economic Theory of Liability," J. Legal Studies, June $1973, \underline{2}, 323-49$.

G. Calabresi, "Some Thoughts on Risk Distribution and the Law of Torts," Yale Law J., Mar. 1961, 70, 499-553.

D. Kennedy, "A History of Law and Economics, or the Fetishism of Commodities," unpublished paper, Harvard Univ., Sept. 1978.

A. M. Polinsky, "Notes on the symmetry of Taxes and Subsidies in Pollution Control," Can. J. Econ., Feb. 1979, 12, 75-83.

Richard A. Posner, Economic Analysis of Law, 2d ed., Boston 1977.

S. Shavell, "Strict Liability vs. Negligence," J. Legal Studies, forthcoming Jan. 1980 .

A. M. Spence and M. L. Weitzman, "Regulatory Strategies for Pollution Control," in Ann F. Friedlaender, ed., Approaches to Controlling Air Pollution, Cambridge 1978.

Richard B. Stewart and James E. Krier, Environmental Law and Policy: Readings, Materials and Notes, 2d ed., Indianapolis 1978.

C. G. Veljanovski, "'Economic' Myths about Common Law Realities-Economic Efficiency and the Law of Torts," work. paper no. 5, Centre for Socio-Legal Studies, Oxford, Mar. 1979.

B. R. Weingast, M. E. McBride and J. L. Conant, "Product Safety and Consumer Information: The Impact of Liability Assignment and Standards Regulation," work. paper no. 45, Center for the Study of Amer. Business, Washington Univ. (St. Louis), June 1979. 